\title{
Acute respiratory distress syndrome caused by Mycoplasma pneumoniae in a child: the role of methylprednisolone and clarythromycin
}

Síndrome do desconforto respiratório agudo causada por Mycoplasma pneumoniae em uma criança: o papel da metilprednisolona e claritromicina

João Fernando Lourenço de Almeida ${ }^{1}$, Adalberto Stape ${ }^{1}$, Eduardo Juan Troster ${ }^{1}$

\begin{abstract}
Mycoplasma pneumoniae is recognized as an important agent of pneumonia in pediatric population. In rare situations, severe pulmonary injury can develop. The use of corticoids in these cases remains controversial. A case of a girl with acute respiratory distress syndrome and bilateral pleural effusion secondary to pneumonia due to Mycoplasma pneumoniae is described, with good recovery after appropriate use of methylprednisolone and clarythromicyn.
\end{abstract}

Keywords: Mycoplasma pneumoniae; Steroids; Child; Acute Respiratory Distress Syndrome; Clarythromicyn; Case reports

\section{RESUMO}

Mycoplasma pneumonia é reconhecido como um importante agente causador de pneumonia em crianças. Raramente pode evoluir para lesão pulmonar grave. 0 uso de corticoide nesses casos ainda é controverso. Descrevemos aqui o caso de uma menina com síndrome do desconforto respiratório agudo e derrame pleural bilateral secundário à pneumonia por Mycoplasma pneumoniae com boa recuperação após utilização de metilprednisolona e claritromicina.

Descritores: Mycoplasma pneumoniae; Esteroides; Criança; Síndrome do Desconforto Respiratório Agudo; Claritromicina; Relatos de casos

\section{INTRODUCTION}

Mycoplasma pneumoniae is a common cause of pneumonia. It accounts for 10 to $20 \%$ of communityacquired pneumonia. The pulmonary infection is often classified as an atypical pneumonia. This can be justified by the clinical presentation that resembles a systemic viral infection. The disease is highly transmissible and infection occurs throughout the year, with clear peaks during the autumn and early winter ${ }^{(1)}$.

In children, $M$. pneumoniae is an agent responsible for upper and lower respiratory infections, often minor and self-limited. It includes cases of pharyngitis, tracheobronchitis, bronchiolitis and pneumonia. Twenty percent of these infections are asymptomatic and mortality is rare ${ }^{(1)}$.

Severe pulmonary injury due to $M$. pneumoniae is extremely unusual and there are few descriptions in the literature of patients who develop pleural effusion or acute respiratory distress syndrome/acute lung injury $(\mathrm{ARDS} / \mathrm{ALI})^{(2-5)}$.

The case of a child with an atypical evolution of pneumonia due M. pneumoniae is described, emphasizing the therapeutic aspects of the disease, such as mechanical ventilation support, antibiotics and the use of corticosteroids for ARDS, with attention to specific indications for $M$. pneumoniae. The basic differences between classical ARDS and ARDS due to M. pneumoniae are also discussed.

\section{CASE REPORT}

A 14-year-old female was transferred to the Pediatric Intensive Care Unit (PICU) with a seven-day history of cough. She had fever and respiratory distress 1 day prior to admission. In her past medical history, only two episodes of pneumonia were diagnosed.

${ }^{1}$ Pediatric Intensive Care Unit of Hospital Israelita Albert Einstein - HIAE, São Paulo (SP), Brazil.

Corresponding author: João Fernando Lourenço de Almeida - Avenida Albert Einstein, 627/701 - CEP 05651-901 - São Paulo (SP), Brasil - Tel.: (11) 2151- 1242 - e-mail: jfalmeida@einstein.br

The authors declare there is no conflict of interest.

Received on: July 14, 2010 - Accepted on: March, 3, 2011 
On admission, she had a respiratory rate of 50 breaths/minute and heart rate of 140 beats/minute, with temperature of $37^{\circ} \mathrm{C}$. Auscultation of the lungs revealed coarse crackles on the right. Laboratory exams showed: hemoglobin $11.5 \mathrm{~g} / \mathrm{dL}$, white blood cell 12,500/ $\mu \mathrm{l}$, neutrophils $55 \%$, and C-reactive protein $445 \mathrm{mg} /$ dL. Her chest radiography showed bilateral diffuse infiltrates (Figure 1A). Ceftriaxone and oxygen therapy were initiated.

After 24 hours, her clinical and respiratory status worsened. The chest radiograph and computerized tomography scan revealed bilateral pleural effusion

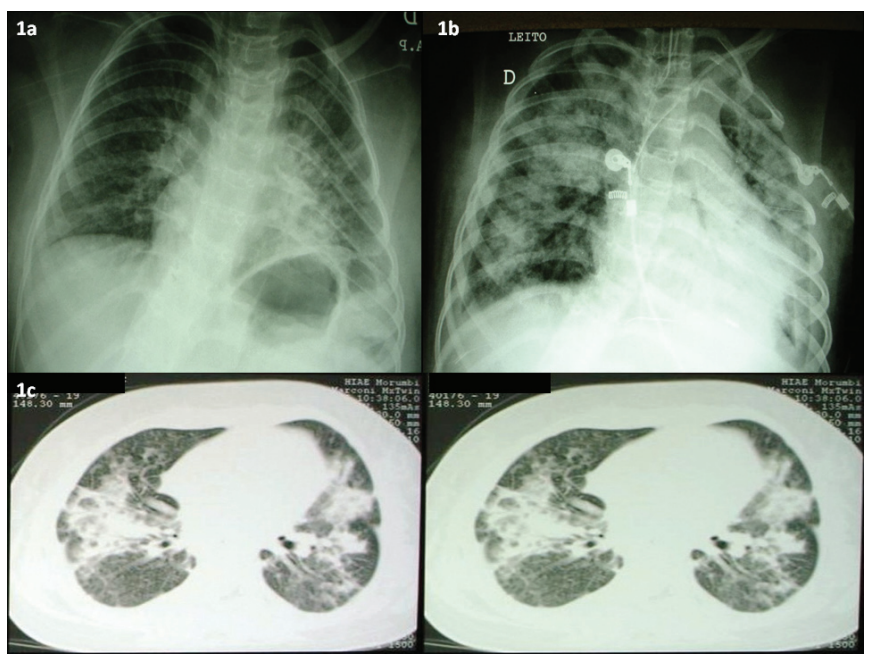

Figure 1. (A) Chest radiography upon admission showing bilateral infiltrate. (B) Radiography on day 2, showing worsening in bilateral infiltrate along with bilateral pleural effusion. (C) Chest computed tomography showing collapsed areas and diffuse pulmonary infiltrate

(greater extension on left side) and increased bilateral infiltrate (Figures 1B and 1C).

She was intubated and mechanically ventilated. The antibiotic scheme was changed to teicoplanin and imipenem. The treatment of pleural effusion was conservative.

Despite the use of higher ventilator settings, her $\mathrm{PaO}_{2} / \mathrm{FiO}_{2}$ was $65 \mathrm{mmHg}$. After combined analysis of the oxygenation status $\left(\mathrm{PaO}_{2} / \mathrm{FiO}_{2}<200 \mathrm{mmHg}\right)$, chest radiography (bilateral infiltrate), acute progression and no evidence of left atrial hypertension, the PICU staff diagnosed an ARDS.

Regarding the ventilator settings, the lung-protective strategy was applied with the use of high PEEP (positive end-expiratory pressure) and lower tidal volume (6 to 8 $\mathrm{mL} / \mathrm{kg}$ ). Despite the use of recruitment maneuvers and PEEP up to $20 \mathrm{cmH}_{2} \mathrm{O}$, the $\mathrm{PaO}_{2} / \mathrm{FiO}_{2}$ ratio remained above $125 \mathrm{mmHg}$. After the increase in the PEEP settings, the patient developed hypotension (treated with fluids and dopamine up to $10 \mathrm{mcg} / \mathrm{kg} / \mathrm{min}$ ).
After 7 days of antibiotics, the patient remained febrile, with no improvement in the $\mathrm{PaO}_{2} / \mathrm{FiO}_{2}$ status. Blood culture, investigation for Pneumocystis carinii and tuberculosis were negative. Serology for M. pneumoniae (indirect microparticle aglutinin) and the test for cold agglutinins were positive. Clarithromycin was initiated.

Even after 48 hours of macrolide use, there was no increase in the oxygenation status.

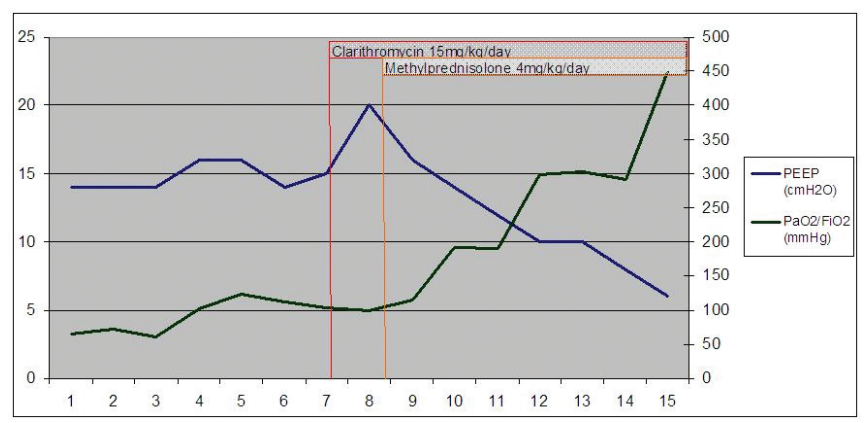

Figure 2. Correlation between PEEP $\left(\mathrm{cmH}_{2} \mathrm{O}\right)$ and $\mathrm{PaO}_{2} / \mathrm{FiO}_{2}(\mathrm{mmHg})$. Red line: initiation of clarithromycin. Orange line: initiation of corticosteroids

After 9 days, corticosteroid therapy was added due to no improvement in $\mathrm{PaO}_{2} / \mathrm{FiO}_{2}$. After 2 days of methylprednisolone use $(4 \mathrm{mg} / \mathrm{kg} /$ day $)$, the $\mathrm{PaO}_{2} / \mathrm{FiO}_{2}$ increased above $200 \mathrm{mmHg}$ (Figure 2).

The anti-inflammatory effect of corticosteroids permitted the reduction of PEEP. On the $14^{\text {th }}$ day the patient was extubated and transferred to the pediatric ward. Clarithromycin was interrupted after 14 days and methylprednisolone after 7 days.

\section{DISCUSSION}

Pneumonia due to $M$. pneumoniae is usually a benign self-limited disease, but severe and fatal cases have been described. In these cases, mortality is higher due to decreased response to therapy ${ }^{(1)}$.

The classical treatment for severe pulmonary infection caused by M. pneumonia include the use of a macrolide, mechanical ventilation and Intensive Care Unit (ICU) support ${ }^{(5)}$.

The therapeutic strategy in mechanical ventilator settings in ARDS due to M. pneumoniae, as with any other agent, should target the use of higher PEEPs and lower tidal volumes. In children, the literature is scarce and the applicability of these strategies should be considered only in selected cases.

In our case, even with the use of higher PEEP (up to $20 \mathrm{cmH}_{2} \mathrm{O}$ ), low tidal volume and lung recruitment maneuvers, the child was not able to restore a normal 
$\mathrm{PaO}_{2} / \mathrm{FiO}_{2}$ after 1 week of these strategies (along with broad spectrum antibiotics).

Regarding the use of steroids for ARDS, a critical appraisal of the ARDS network trial and recent literature was conducted by Meduri et al. ${ }^{(6)}$ and the conclusion was that prolonged use of corticosteroids ( $\geq 7$ days) improves patient-centered outcome variables, such as improvement in gas exchange, reduction in markers of inflammation and decreased duration of mechanical ventilation and ICU stay. If initiated before day 14 of ARDS, the use of steroids can have an additional survival benefit.

This potential benefit of steroids for ARDS seems to be more important in severe cases of pneumonia due to $M$. pneumoniae. Evidence points to the strong consideration of steroid use in ARDS/ALI due to $M$. pneumoniae or severe pneumonia ${ }^{(2-5)}$. Due to the delay in starting methylprednisolone treatment, the present case is very illustrative in this aspect, since it shows the amazing recovery after the steroid use.

The potential benefit of steroids in these cases is consistent with the hypothesis that cell-mediated immunity plays an important role in M. pneumoniae pneumonia. This was demonstrated by the presence of mononuclear perilumenal infiltrates on lung tissue ${ }^{(7)}$. Also, there are studies that show low incidence of M. pneumoniae pneumonia in immunocompromised patients ${ }^{(8)}$.

On immunocompetent patients, the severe cases of pneumonia due to $M$. pneumoniae could be explained by the fact that stronger cellularimmunological responses may induce more severe pneumonic infiltrates, mainly in patients with repetitive community-acquired infections ${ }^{(9)}$. Unlike the histological pattern of classical ARDS, primary centered on neutrophil migration into the airways, this response in $M$. pneumoniae infection is deemed as a "lymphoid" ARDS, considering that the more vigorous the cytokine and the cell-mediated immune response, the more severe is the pulmonary injury ${ }^{(2)}$.

Summarizing, corticosteroids downregulate the cellmediated response and therefore may play an important role in severe pneumonia due to $M$. pneumoniae. The question that has to be answered is which patients should receive steroids and how to identify them.
Narita et al. reported that higher concentrations of interleukin 18 (IL-18) and interleukin 8 (IL-8) in serum or pleural fluid samples of patients in acute phase of $M$. pneumoniae infection were closely associated with severity of the disease. The authors recommend that IL-8 and IL-18 should be measured (in serum or pleural fluid) and could be used as predictors for disease severity in $M$. pneumoniae pneumonia and help deciding whether to use or not corticosteroids ${ }^{(10)}$.

In conclusion, even though still controversial for all cases of ARDS, there is clear evidence in the literature of reliable use of corticosteroids in extremely severe cases of M. pneumoniae ARDS. Other patients with less severe cases could benefit from steroid use, but the application should be considered as an option, due to weak evidence. Hence, further studies are necessary to confirm the benefit and to address other important questions regarding which patients are candidates for use, the ideal dose and timing of methylprednisolone.

\section{REFERENCES}

1. Waites KB. New concepts of Mycoplasma pneumoniae infections in children. Pediatr Pulmonol. 2003;36(4):267-78.

2. Radisic M, Torn A, Gutierrez P, Defranchi HA, Pardo P. Severe acute lung injury caused by Mycoplasma pneumoniae: potential role for steriod pulses in treatment. Clin Infect Dis. 2000;31(6):1507-11.

3. Takiguchi Y, Shikama N, Aotsuka N, Koseki H, Terano T, Hirai A. Fulminant Mycoplasma pneumoniae pneumonia. Intern Med. 2001;40(4):345-8.

4. Yoshinouchi T, Ohtsuki Y, Fujita J, Sugiura Y, Banno S, Sato S, et al. A study on intraaveolar exudates in acute Mycoplasma Pneumoniae infection. Acta Med Okayama. 2002;56(2):111-6.

5. Lee KL, Lee HS, Hong JH, Lee MH, Lee JS, Burgner D, et al. Role of prednisolone treatment in severe Mycoplasma pneumoniae pneumonia in children. Pediatric Pulmonol. 2006;41(3):263-8.

6. Meduri GU, Marik PE, Chousos GP, Pastores SM, Arlt W, Beishuizen A, et al. Steroid treatment in ARDS: a critical appraisal of the ARDS network trial and the recent literature. Intensive Care Med. 2008;34(1):61-9.

7. Cimolai N, Taylor GP, Mah D, Morrison BJ. Definition and application of a hispathological scoring scheme for an animal model of acute Mycoplasma pneumoniae pulmonary infection. Microbiol Immunol. 1992;36(5):465-78.

8. Tarp B, Jensen JS, Ostergaard L, Anderson PL. Search for agents causing atypical pneumonia in HIV-positive patients by inhibitor-controlled PCR assay. Eur Respir J. 1999;13(1):175-9.

9. Cimolai N. Corticosteroids and complicated Mycoplasma pneumoniae infection. Pediatric Pulmonol. 2006;41(10):1008-9.

10. Narita M, Tanaka H. Cytokines involved in the severe manifestations of pulmonary diseases caused by Mycoplasma pneumoniae. Pediatr Pulmonol. 2007:42(4):397. 